\title{
A TEORIA DA SUBJETIVIDADE E O TRANSTORNODO ESPECTRO AUTISTA: O QUE JÁ FOI PESQUISADO?
}

la Fernanda Wunder da Silva ${ }^{(*)}$ Marlene Rozek ${ }^{(* *)}$

\section{INTRODUÇÃO}

[...] o saber é sempre o saber de alguém que trabalha alguma coisa no intuito de realizar um objetivo qualquer. Além disso, o saber não é uma coisa que flutua no espaço: o saber dos professores é o saber deles e está relacionado com a pessoa e a identidade deles, com a experiência de vida e com a sua história profissional, com suas relações com os alunos em sala de aula e com os outros atores escolares na escola, etc. Por isso, é necessário estudá-lo relacionando-o com esses elementos constitutivos do trabalho docente (TARDIF, 2002, p. 11).

A realização deste mapeamento tem como objetivo principal subsidiar futuras pesquisas na área da educação que tenham como temática de estudo o Transtorno do Espectro Autista (TEA) e a Teoria da Subjetividade (TS) como proposta por Fernando González Rey (2005, 2009, 2017). O campo de pesquisa na área do TEA ainda é bastante vinculado às questões comportamentais e ligado à área da saúde, ou são realizados diferentes estudos teóricos a respeito da compreensão do que seria o TEA e como se apresenta este transtorno nas pessoas.

Estudar o TEA a partir da Teoria da Subjetividade elaborada por González Rey (1997, 2003, 2005, 2007, 2017) em uma perspectiva histórico-cultural propicia um novo referencial teórico e epistemológico para compreender este indivíduo e sua gama de diversidades, descolando um pouco do olhar biológico, que aponta as características como oriundas de um funcionamento inadequado do cérebro, ou da presença ou ausência de genes. Não se questiona a diferença e importância destes estudos, mas aponta-se que as diferenças entre os indivíduos, incluindo os com TEA faz parte da

\footnotetext{
${ }^{(*)}$ Mestre e doutoranda em Educação pela PUCRS, Pedagoga Especial e Psicopedagoga. Integrante do Núcleo de Estudos e Pesquisas sobre Aprendizagem e Processos Inclusivos (NEPAPI) na PUCRS. Orcid: https://orcid.org/00000002-8350-0726>. E-mail. karla.silva@acad.pucrs.br.

${ }^{(* *)}$ Doutora em Educação. Professora do Curso de Pedagogia e do Programa de Pós-Graduação em Educação da Escola de Humanidades da PUCRS. Coordenadora do Núcleo de Estudos e Pesquisas sobre Aprendizagem e Processos Inclusivos (NEPAPI) na PUCRS. Coordena o LEPNEE (Laboratório de Ensino e Atendimento às Pessoas com Necessidades Específicas) PUCRS. Orcid: https://orcid.org/0000-0001-8740-6166>.E-mail. marlene.rozek @ pucrs.br,
} 
constituição subjetiva de cada um, levando em conta também, como isso é visto pela sociedade em que o individuo encontra-se fazendo parte.

A Teoria da Subjetividade na perspectiva proposta necessita e exige uma reflexão aprofundada dos processos de constituição dos indivíduos, que precisam ser vinculadas as experiências vividas, que podem se tornar compreensíveis através de uma integração dos processos subjetivos que se reportam ao desenvolvimento individual e social significativo e singular. Validamente, a proposta de González Rey $(2005,2009$, 2017) que se volta para o estudo da subjetividade humana mostrar-se como uma possibilidade de analisar sobre esta ótica a diversidade humana, na sua constituição enquanto sujeito. Um dos objetivos é compreender o Transtorno do Espectro Autista também como processo subjetivo, que não pode ser desconectado das experiências sociais e culturais que rodeiam o ser humano.

Ao entendermos o TEA apenas como oriundo de aspectos neurobiológicos, comportamentais ou como um transtorno do neurodesenvolvimento infantil, que difere apenas de intensidade, estamos negando a subjetividade que é constitutiva do ser humano, que é a força da produção mais genuína do ser humano e nos submetendo apenas as questões instrumentais do transtorno (GONZÁLEZ REY, 2007).

Falar da pessoa com Transtorno do Espectro Autista na perspectiva da Teoria da Subjetividade nos faz questionar como se desenvolvem os processos de subjetivação do indivíduo, que recursos pessoais ele adquire para avançar em seu desenvolvimento realizando escolhas e não apenas reproduzindo ações ou pensamentos dos outros que o atendem (GONZÁLES REY, 2011).

Para realizar este mapeamento de produções científicas sobre o assunto proposto entendermos que ela passa antes de tudo pela compreensão científica que acessar estes diferentes documentos, delimitados por um período de tempo e assunto específico é realizar uma revisão bibliográfica, que irá sustentar a pesquisa científica. Esta revisão deve acessar diferentes fontes que deem sustentação ao pretendido como: artigos em periódicos científicos, livros, teses, dissertações e resumos em congresso (MEDEIROS; TOMASI, 2008).

A revisão bibliográfica é um movimento inicial indispensável para qualquer ato de estudo científico, pois possibilita que se tenha uma ideia inicial sobre os acontecimentos no acampo a ser pesquisado, sobre o tema e sobre as lacunas que ainda existes no mesmo evidenciando a possível contribuição ou não da temática para o campo do estudo (MARCONI; LAKATOS, 2008).

Para organizar as diferentes fontes consultadas, as informações coletadas, utilizou-se neste artigo a pesquisa definida como Estado do Conhecimento que tem um caráter bibliográfico e 
qualitativo, e permitindo discutir e responder que aspectos vêm sendo destacados e privilegiados em diferentes produções científicas, de que formas e em que condições as mesmas tem sido produzidas. (FERREIRA, 2002).

O estado do conhecimento tem características que dão sustentação para o pesquisador no caminho escolhido e na temática elencada. Segundo Morosini (2015):

um estado de conhecimento é identificação, registro, categorização que levem à reflexão e síntese sobre a produção científica de uma determinada área, em um determinado espaço de tempo, congregando periódicos, teses, dissertações e livros sobre uma temática específica (p. 102)

A realização do 'estado do conhecimento' envolve etapas importantes que qualificam este processo que foram elencados segundo Romanowski e Ens (2006) como: definir os descritores para poder direcionar as buscas; estabelecer critérios claros para a busca do material que irá compor o corpus da pesquisa; elencar as teses e dissertações que farão parte deste corpus; organizar um quadro ou relatório com a sistematização das pesquisas e artigos encontrados de acordo os temas abordados nos documentos.

\section{DESENVOLVIMENTO}

Para a construção deste artigo, houve a necessidade de uma maior articulação de diferentes formas de busca dos descritores em bancos de dados distintos, na tentativa de encontrar produções que respondessem a esses descritores. Nesta articulação foram elencados estudos de mestrado e doutorado que ocorreram entre 2013 até 2018, assim como produções científicas com o mesmo limite de tempo (artigos científicos). Esta escolha temporal justifica-se pela publicação do Manual de Diagnóstico e Estatístico de Transtornos Mentais1, 5a edição (DSM-5) que ocorreu em 18 de maio de 2013, alterando a nomenclatura do Autismo para Transtorno do Espectro Autista (TEA). Este levantamento do que já foi e está sendo estudado por diferentes pesquisadores em diferentes Universidades foi realizado na plataforma do Instituto Brasileiro de Informação em Ciência e Tecnologia $^{2}$ (IBICT), da plataforma da Comissão de Aperfeiçoamento de Pessoal do Nível

\footnotetext{
${ }^{1}$ Manual de Diagnóstico e Estatística dos Transtornos Mentais 5. edição ou DSM-5 é um manual organizado pela Associação Americana de Psiquiatria para auxiliar no diagnóstico de transtornos mentais. Utilizado muito na área da saúde (médicos, psicólogos, terapeutas ocupacionais, etc.) A versão atualizada saiu em maio de 2013 e substitui o DSM-IV criado em 1994 e revisado em 2000. Desde o DSM-I, criado em 1952, esse manual tem sido uma das bases de diagnósticos de saúde mental mais usado no mundo.

${ }^{2} \mathrm{http}: / /$ www.ibict.br/
} 
Superior $^{3}$ (CAPES), Universidade de $\operatorname{Brasília}^{4}(\mathrm{UnB})$ e, por fim, na busca de artigos científicos foi utilizado o repositório de artigos da Scientific Electronic Library Online ${ }^{5}$ (Scielo). Os descritores utilizados foram:

1.Transtorno do Espectro Autista (TEA) X Subjetividade

2. Transtorno do Espectro Autista (TEA)

3. Subjetividade (sentidos subjetivos, constituição subjetiva).

Numa busca geral inicial com o cruzamento dos dois descritores caso 1, não foi encontrada produções científicas nos bancos de dados visitados. Foram encontradas produções no isolamento dos termos como o descritor 2 (Transtorno do Espectro Autista) e descritor 3 (Subjetividade). A mesma situação se repetiu no banco de dados de artigos científicos, com produções sendo encontradas apenas quando isolados os descritores.

Desta forma, em um primeiro momento de leitura flutuante com o descritor 2. TEA foram encontrados em uma busca geral 307 trabalhos. Em uma busca avançada, acrescentando um limite de tempo (2013-2018) foram encontrados 23 trabalhos. Com este descritor (Gráfico 1) foram encontradas no período anunciado as seguintes produções: no ano de 2013 não foi encontrado nenhum trabalho, no ano de 2014, 04 dissertações e 02 teses; no ano de 2015, 08 dissertações e 02 teses; e no ano de 2016 foram encontradas 06 dissertações e 01 tese.

Gráfico 1: Pesquisa com descritor "TEA” Banco de dados CAPES e IBICT (2018)

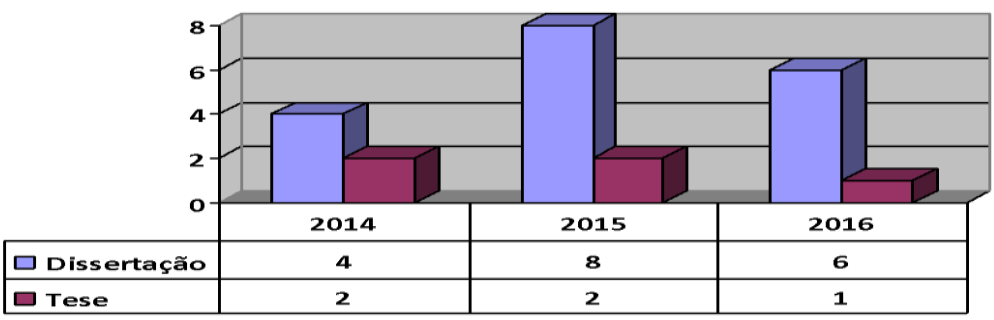

$\square$ Dissertação

$\square$ Tese

Fonte: Autora (2018)

Realizando um somatório entre os anos, chega-se ao resultado de 23 trabalhos ao todo com o descritor "Transtorno do Espectro Autista" como citado anteriormente (gráfico 2), sendo que destes,

\footnotetext{
${ }^{3} \mathrm{Vr}:<\mathrm{http}: / /$ bancodeteses.capes.gov.br/banco-teses/\#!/>.

${ }^{4}$ A inclusão da plataforma da Universidade de Brasília foi necessária em função das pesquisas relacionadas a $\mathrm{T}$ eoria da Subjetividade já que lá é o lócus onde esta temática é mais pesquisada na atualidade. http:// www.bce.unb.br/bibliotecas-digitais/repositorio/teses-e-dissertacoes/> e www.scielo.org/.
} 
18 são dissertações e 5 são teses de diferentes áreas do conhecimento e tendo a predominância dos estudos em universidades de São Paulo (16) e do Rio Grande do Sul (4) sendo as restantes distribuídas entre três outros estados, Rio Grande do Norte, Alagoas e Amazonas, com 1 pesquisa em cada estado.

Gráfico 2: Pesquisa com descritor "TEA" demarcando dissertações e teses no Banco de dados CAPES e IBICT (2018)

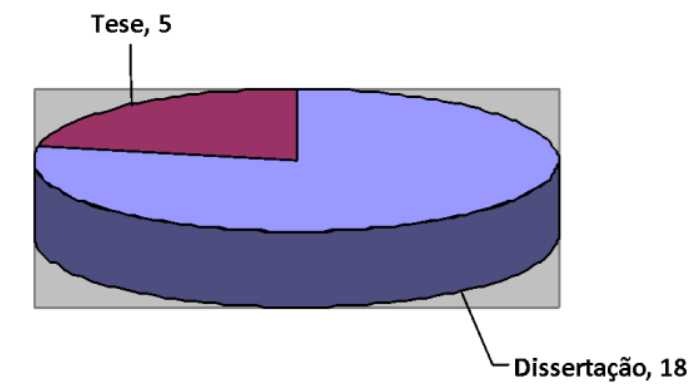

Fonte: Autora (2018)

O tema Transtorno do Espectro Autista tem sido abordado por diferentes pesquisadores (Gráfico 3), mas pouco ainda referendado e analisado por parte da Educação como se propõe este levantamento de dados. A temática da Subjetividade e o TEA precisam ser estudados e aprofundados no viés da Educação. Foram encontradas dissertações e teses que versavam sobre as seguintes áreas do conhecimento: Psicologia (11); Fonoaudiologia (2), Informática (1), Veterinária (1), Ciências Biológicas (1) e, finalmente, na área da Educação foram encontradas 7 exemplares. Sendo prioritariamente a área da Educação o foco desta pesquisa, foram então elencadas as 7 pesquisas encontradas nesta busca para constarem neste corpus teórico e serem analisadas de forma mais detalhada.

Gráfico 3: Pesquisa com descritor "Transtorno do Espectro Autista" demarcando áreas do conhecimento no Banco de dados CAPES e IBICT (2018)

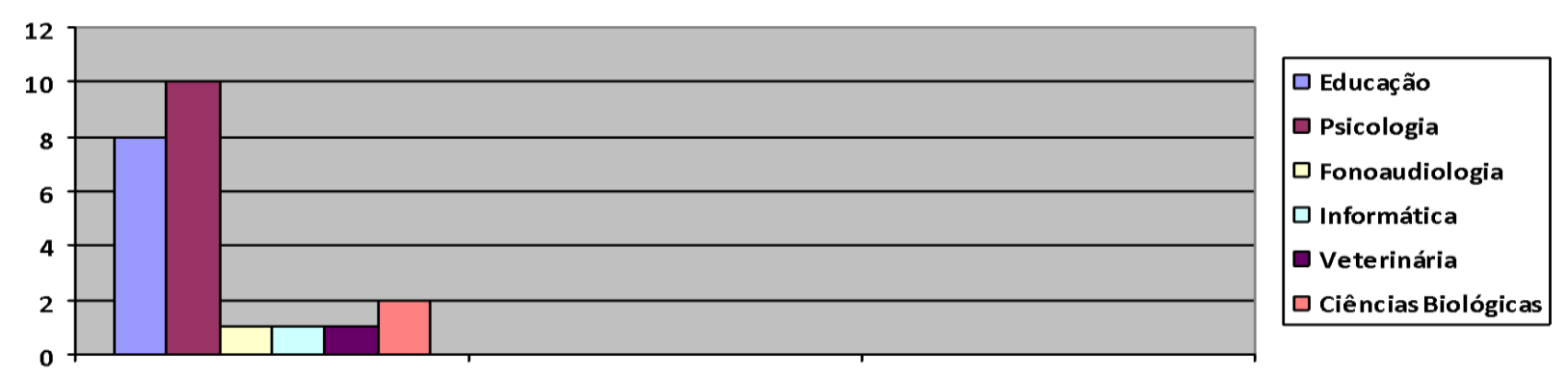

Fonte: Autora (2018) 
É importante destacar que as temáticas abordadas nas 7 pesquisas encontradas que tratam sobre TEA no viés da Educação, sustentam a posição da possível inteligibilidade ${ }^{6}$ que se abre no campo, ao cruzar conceitos como TEA e Subjetividade, uma vez que não há publicações que levem em conta estes descritores em cruzamento. Nenhumas das pesquisas, que serão apresentadas a seguir são similares a perspectiva pretendida apresentada inicialmente.

As pesquisas aqui expostas enfocam as práticas pedagógicas como planejamento pedagógico e participação do aluno com TEA nas atividades; a fragilidade ainda da inclusão dos alunos que apresentam um quadro de TEA (RAMOS, 2014.). Outra pesquisa realizada foi a respeito dos irmãos de indivíduos com TEA (RODRIGUES, 2015), apontando a importância que toma o diagnóstico do transtorno para a família deste indivíduo, salientando que, muitas vezes, os irmãos acabam também desenvolvendo problemas psicológicos ou uma maturidade cognitiva e social muito mais acelerada do que o previsto em virtude da carga emocional envolvida no cotidiano desta família. A Experiência de Aprendizagem Mediada como uma proposta de intervenção para alunos com TEA, baseada na Teoria de Feuerstein também aparece em uma das pesquisas (MÂCEDO, 2015), trazendo como contribuição que uma proposta organizada e pensada para o sujeito com TEA mediada pelo adulto, gera resultados significativos de avanços em suas conquistas cognitivas.

O ensino da matemática aparece em uma das pesquisas (TAKINAGA, 2015) utilizando-se da Teoria da Atividade e dos conceitos de mediação explanados por Engeström, apresentando como resultado que $68 \%$ das instituições investigadas a partir das propostas de atividades oferecidas por professores de matemática à alunos com TEA, prevalece a utilização de metodologias comportamentais. Os processos formativos dos professores que atendem alunos que apresentam um quadro de TEA, buscando significados e sentidos acerca do TEA mesmo e como e como esses processos formativos produzem transformações nas práticas pedagógicas dos professores (PEREIRA, 2016) é outra das pesquisas encontradas. Em suas conclusões a autora trata sobre o ecletismo epistemológico, ou seja, a diversidade de teorias apresentadas nas diversas formações aos professores, poucas com condições reais de aplicabilidade no ensino regular e sem um aprofundamento significativo de seus preceitos teóricos para que pudessem realmente provocar mudanças nas práticas pedagógicas. .

\footnotetext{
${ }^{6}$ Inteligibilidade pode ser entendida como uma nova percepção, uma nova forma de ver a situação pesquisada, que não é a simples representação do mundo exterior, mas uma relação do mundo e experiências, sentimentos e impressões, diferente de tudo visto antes, que acaba gerando novas práticas que influenciam e acabam por modificar o problema que está sendo estudado. (GONZÁLEZ REY, 2007).
} 
O aprofundamento das questões sobre a escolarização de alunos com TEA (SANTOS, 2016; RINALDO, 2016) também foram temas de pesquisas. Tratando da dicotomia existente entre o que diz a lei sobre os processos inclusivos e a realidade que se apresenta nas escolas que efetivamente colocam em prática preceitos e indicações inclusivas, bem como a análise da inclusão de alunos com TEA na educação infantil. As pesquisas pontuam que a inclusão na etapa da Educação Infantil tende a ter mais resultados positivos desde que o planejamento realizado pelos professores seja voltado para o aluno real e não para o imaginado pelas características do transtorno em questão, expondo um sistema educacional ainda frágil e despreparado, mesmo que eticamente tenha o entendimento do direito deste aluno ser acolhido pelo sistema regular de ensino.

Percebe-se então que as pesquisas aqui apresentadas (RAMOS, 2014; RODRIGUES, 2015; MÂCEDO, 2015; TAKINAGA, 2015; PEREIRA, 2016; RINALDO, 2016; SANTOS, 2016.) destinam a análise para a dificuldade da educação do sujeito com TEA e para as relações familiares. Contudo, nada é pautado a respeito da subjetividade desse sujeito, o que o marca como alguém diferente, não pela patologia que apresenta, mas pelas configurações subjetivas que construiu e constrói em sua vida.

Entendemos como configurações subjetivas, a partir da Teoria da Subjetiva, as formas complexas em que os sentidos subjetivos são organizados, que por sua vez são produzidos nos processos de subjetivação individual e social de cada pessoa, que tem em seu desdobramento simbólico-emocional, um movimento individual, mas também permeado pelas relações sociais dos espaços que ocupa em sua sociedade (GONZÁLES-REY, 2003).

Complementando a pesquisa, utilizou-se a plataforma Scielo na busca de textos científicos publicados em periódicos ainda com o descritor Transtorno do Espectro Autista, na qual foram encontrados no período de tempo demarcado, 35 artigos científicos sobre a temática. Este levantamento vem corroborar com as constatações já realizadas que pouco tem se produzido em educação a respeito da temática, pois da totalidade dos artigos selecionados para estudo, apenas 5 são referentes à Educação. O maior número de artigos publicados entre 2013 - 2018 foram na área da Saúde, 29 ao todo, estando subdivididos da seguinte forma: na área da Fonoaudiologia foram encontrados 9 artigos, na Psicologia também 9 artigos e na área médica (Genética, Pediatria, Neurologia) encontrou-se 11 artigos. Cabe salientar que destes 35 artigos científicos publicados, 12 deles (da área da saúde, com maior quantidade da medicina) foram publicados em língua estrangeira (inglês). 
Gráfico 4: Pesquisa com o descritor "Transtorno do Espectro Autista" no site SCIELO com produção de artigos científicos agrupados por ano.

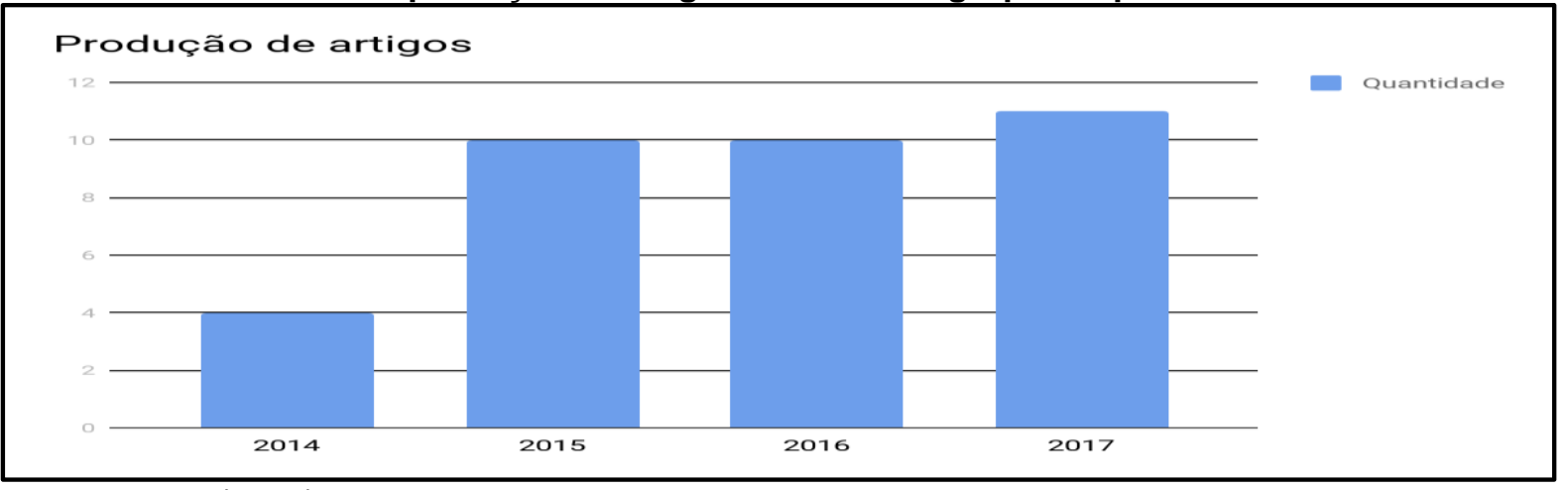

Fonte: Autora (2018)

Percebe-se com a disposição das produções no gráfico 4 que a publicação a respeito do TEA tem se ampliado durante os anos. Depreendo que isso ocorre em função da necessidade de estudo e informações para dar conta das particularidades de atendimento deste sujeito. Isolando os artigos científicos que tratam sobre Educação, identifica-se apenas 5 produções em que a temática principal é o TEA, mas com enfoque diferentes da proposta de pesquisa pretendida neste estudo, como podese ver na tabela 1 e todos eles publicados no ano de 2017. As temáticas abordadas nos artigos elencados abaixo transitam nas questões sobre inclusão dos alunos com TEA, políticas públicas, socialização e uso de tecnologias como facilitadoras da aprendizagem.

TABELA 1: Artigos Científicos encontrados no site SCIELO com descritor "TEA".

\begin{tabular}{|l|l|c|}
\hline TÍTULO & AUTORES & ANO \\
\hline $\begin{array}{l}\text { Alunos autistas: análise das possibilidades de interação social } \\
\text { no contexto pedagógico }\end{array}$ & MARTINS; MONTEIRO. & 2017 \\
\hline $\begin{array}{l}\text { Inclusão Escolar de crianças com Transtorno do Espectro } \\
\text { Autista: uma revisão sistemática da literatura. }\end{array}$ & CABRAL; MARIN. & 2017 \\
\hline $\begin{array}{l}\text { Políticas para o autismo no Brasil: entre a atenção psicossocial } \\
\text { e a reabilitação. }\end{array}$ & OLIVEIRA et al & 2017 \\
\hline $\begin{array}{l}\text { Tecnologias Móveis na Inclusão Escolar e Digital de Estudantes } \\
\text { com Transtornos de Espectro Autista }\end{array}$ & SANTAROSA; CONFORTO. & 2015 \\
\hline $\begin{array}{l}\text { A Influência de práticas pedagógicas e terapêuticas não verbais } \\
\text { no transtorno do espectro autista: as possibilidades para o } \\
\text { profissional de educação física }\end{array}$ & LIMA et al. & 2017 \\
\hline
\end{tabular}

Com o descritor3- Subjetividades, em uma busca geral, foram encontrados 21.470 trabalhos. Contudo, para que a busca fosse mais assertiva, foi necessário um acréscimo de termos que articulasse conceitos da perspectiva teórica alvitrada, ou seja, a Teoria da Subjetividade proposta por Fernando Gonzáles Rey (1997, 2015, 2017a). Foi preciso acrescentar em uma busca avançada, termos próprios desta teoria como: Sentidos Subjetivos, Constituição Subjetiva. Manteve-se o corte temporal de 2013 a 2018 para sustentar um critério que unisse os diferentes descritores. Acrescentou-se para esta busca de produções o site da Universidade de Brasília (UNB), 
instituição na qual o autor da Teoria da Subjetividade, Fernando Gonzáles Rey encontra-se até o momento, vinculado com produções acadêmicas, orientações e grupos de estudos.

Os trabalhos encontrados no site da CAPES e IBICT concentraram-se em três anos (2014, 2015 e 2016), sendo que ao todo foram encontrados 18 trabalhos (Gráfico 5) entre dissertações e teses que tratam sobre Subjetividade na perspectiva supra citada. Nestas 18 produções encontradas, as áreas de conhecimento que apareceram foram Educação (6), Psicologia (11) e Linguística (1).

Gráfico 5: Pesquisa com descritor "Subjetividade, sentidos subjetivos, constituição subjetiva" no Banco de dados CAPES, IBICT (2018)

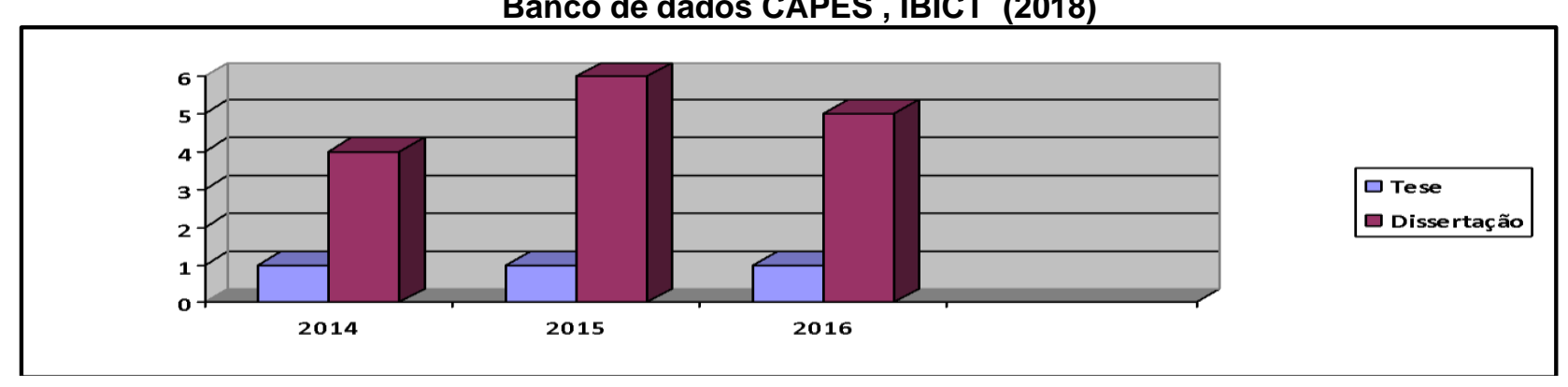

FONTE: Autora (2018)

Realizando uma busca no site da Universidade de Brasília (UnB), foram encontradas 27 produções no período de 2013 - 2018. De todas as pesquisas apresentadas, apenas 3 constam também no site da CAPES. Novamente, ao realizarmos um somatório do material encontrado vemos que 17 destas produções são na área da Educação e as demais são vinculadas a Psicologia, Sociologia, Comunicação Social, Direito, Educação Física, Ciência do Comportamento e Processo do Desenvolvimento Humano e Saúde.

Após a análise, percebe-se que o maior número de estudos realizados é em Programas de Pós Graduação Stricto Sensu em Educação, contudo, eles não tratam especificamente de temáticas voltadas para os aspectos educacionais, ou seja, planejamento, metodologia, relações em sala de aula, aprendizagens em suas diferentes modalidades. A maioria trata sobre a perspectiva dos professores a respeito da Educação e o sentido que esta escolha profissional tem em suas vidas.

De todas as pesquisas analisadas para o Estado do Conhecimento deste estudo, no que se refere a Teoria da Subjetividade, apenas um dos trabalhos encontrados trata de alguma forma sobre a aprendizagem e subjetividade, sem contudo voltar-se para o TEA. Não foram encontradas pesquisas que apresentem a temática escolhida para esta proposta de tese. Isso aponta claramente para uma nova inteligibilidade a ser constituída (GONZÁLEZ REY, 2003) mediante este estudo, a respeito do sujeito com TEA. Outra perspectiva de compreender este sujeito, a partir da Teoria da 
Subjetividade, gerando novos aportes teóricos e possibilidades de compreensão do sujeito com TEA.

Na dissertação de mestrado encontrada, Bezerra (2014) apresenta sob a luz da Epistemologia Qualitativa e da Teoria da Subjetividade os fenômenos sobre o aprender e o não aprender, colocando o sujeito em um papel ativo de sua aprendizagem, constituído historicamente em suas relações. A autora procura apresentar o desenvolvimento intelectual e, todas as nuances que interferem neste processo como um aspecto que se organiza num curso de subjetividade e suas complexas configurações e não como algo somente vinculado às representações mentais. O estudo possibilitou que as dificuldades de aprendizagem pudessem ser vistas para além de uma patologia estanque, mas compreendidas a partir de uma processualidade e dos diferentes estados afetivos que caracterizam a aprendizagem, favorecendo, assim, a não naturalização dos problemas de aprendizagens.

Desta forma, fica mais clara e presente a intenção de olhar para o sujeito com TEA a partir da Teoria da Subjetividade de Gonzáles-Rey buscando novas possibilidades de entendimento deste individuo, que não o leve, a robotização ou a mecanização das ações, percebendo assim como Bezerra (2014) o fez em sua dissertação como um processo que se trama no curso da constituição da subjetividade individual e das complexas configurações subjetivas da pessoa com TEA.

Finalizando, apresento os artigos científicos publicados no banco de dados da SCIELO, demarcando o descritor 'subjetividade'. Nesta pesquisa, encontrou-se 6 artigos publicados (Tabela 2), em diferentes periódicos que tratam sobre subjetividade na perspectiva apresentada neste artigo.

Tabela 2: Artigos científicos encontrados no site SCIELO com o descritor "Subjetividade".

\begin{tabular}{|l|l|c|}
\hline TÍTULO & AUTORES & ANO \\
\hline $\begin{array}{l}\text { Una epistemología para el estudio de la subjetividad: sus implicaciones } \\
\text { metodológicas }\end{array}$ & $\begin{array}{l}\text { GONZÁLES REY; } \\
\text { MARTINEZ MITJÁNS. }\end{array}$ & 2016 \\
\hline $\begin{array}{l}\text { O trabalho pedagógico criativo na educação infantil diante da cultura } \\
\text { da mídia e do consumo. }\end{array}$ & $\begin{array}{l}\text { MOMO; MARTINEZ } \\
\text { MITJÁNS. }\end{array}$ & 2017 \\
\hline $\begin{array}{l}\text { Desenvolvimento da subjetividade: análise de histórias de superação } \\
\text { das dificuldades de aprendizagem. }\end{array}$ & $\begin{array}{l}\text { ROSSATO; MARTINEZ } \\
\text { MITJÁNS. }\end{array}$ & 2013 \\
\hline $\begin{array}{l}\text { As Pesquisas sobre aprendizagem em museus: uma análise sob a ótica } \\
\text { dos estudos da subjetividade na perspectiva histórico-cultural }\end{array}$ & $\begin{array}{l}\text { ALMEIDA; MITJÁNS } \\
\text { MARTÍNEZ. }\end{array}$ & 2014 \\
\hline $\begin{array}{l}\text { A Subjetividade social da escola e os desafios da inclusão de alunos } \\
\text { com desenvolvimento atípico }\end{array}$ & $\begin{array}{l}\text { SANTOS; } \\
\text { MARTÍNEZ. MITJÁNS }\end{array}$ & 2016 \\
\hline $\begin{array}{l}\text { A Expressão da criatividade na aprendizagem da leitura e da escrita: } \\
\text { um estudo de caso }\end{array}$ & $\begin{array}{l}\text { MUNIZ; } \\
\text { MARTÍNEZ. }\end{array}$ & 2015 \\
\hline
\end{tabular}


Dos artigos científicos apresentados acima, dois se destacam por uma aproximação com a temática, tratando não do mesmo sujeito em questão, mas dos aspectos de aprendizagem dos alunos com deficiência. No primeiro, tendo como autoras Rossato e Martínez Mitjáns (2013) o enfoque é, prioritariamente, as dificuldades de aprendizagem e a forma como podem ser encaradas e superadas através da Teoria da Subjetividade. Já, o artigo das autoras, Santos e Martínez Mitjáns (2016), aborda o conceito de subjetividade social num processo inclusivo de alunos com desenvolvimento atípico, como um arcabouço conceitual que pode influenciar a fluidez do processo inclusivo.

Novamente a abordagem da Teoria da Subjetividade não é trazida para os alunos com TEA, mesmo que haja uma aproximação teórica entre os artigos. Desta forma, o que se observa, por meio do levantamento dos estudos analisados até este momento, é que as pesquisas a respeito do Transtorno do Espectro Autista ainda são escassas e muito voltadas para a área da saúde, não propiciando um pensar aprofundado da Educação para este sujeito.

\section{CONSIDERAÇÕES FINAIS}

Este mapeamento dos estudos realizados acerca do TEA e a Teoria da Subjetividade, apresenta diversas pesquisas (dissertações e teses) bem como artigos científicos que tratam de diferentes ângulos do TEA e da própria subjetividade, sem, contudo, apresentar em nenhum momento uma convergência entre os temas, confirmando a importância deste para se estabelecer um novo campo de estudo a respeito do TEA, gerando uma nova inteligibilidade a respeito deste transtorno vinculado à Teoria da Subjetividade.

Pensar no desenvolvimento subjetivo das pessoas com TEA representa um novo caminhar, uma nova postura, outra forma de encarar e superar os critérios tão bem especificados pela saúde a respeito deste sujeito. É possibilitar, na medida do possível a despadronização para que se possa levar em conta a singularidade do processo de desenvolvimento. O desenvolvimento da subjetividade é um processo contínuo e permanente, de diferentes configurações subjetivas, que se constroem nos mais variados espaços sociais.

Os indivíduos se desenvolvem enfrentando desafios que incluem o desenvolvimento de novos recursos subjetivos que impactam, de uma forma ou de outra, diferentes esferas de sua vida. Diante de situações de conflito, há indivíduos que emergem enquanto sujeitos da situação enquanto outros se subordinam passivamente a ela. Esse é um exemplo que caracteriza o desenvolvimento subjetivo e que não há qualquer área da vida ou qualquer atividade que poderia ser considerada como a única promotora do 
desenvolvimento. O desenvolvimento da subjetividade é sempre um processo autogerador. (GONZÁLEZ REY; MITJÁNS MARTÍNEZ; ROSSATO; GOULART, 2017, p. 306). 


\section{BIBLIOGRAFIA}

AMERICAN PSYCHIATRIC ASSOCIATION (APA). DSM-5 TR: Manual de diagnóstico e estatístico dos transtornos mentais. Porto Alegre: Artes Médicas, 2013.

BEZERRA, Marília dos Santos. Dificuldade de aprendizagem e subjetividade: para além das representações hegemônicas do aprender. 2014. 157 f., il. Dissertação (Mestrado em Educação)—Universidade de Brasília, Brasília, 2014.

CABRAL, Cristiane Soares; MARIN, Angela Helena. Inclusão Escolar de crianças com Transtorno do Espectro Autista: uma revisão sistemática da literatura. Educação em Revista, [s.1.], v. 33, p.1-30, 2017. Disponível em: <http://www.scielo.br/scielo.php?script=sci_arttext\&pid=S0102-46982017000100113\&lng=pt\&tlng=pt>. Acesso em: 05 dez. 2017.

FERREIRA, Norma Sandra de Almeida. As pesquisas denominadas "estado da arte". Educação \& Sociedade, Campinas, ano 23, n. 79, p. 257-272, ago. 2002. Acesso em: 19 fev. 2018.

GONZÁLES REY, Fernando; MARTÍNEZ MITJÁNS, Albertina. Subjetividade Teoria, Epistemologia e método. Editora Alínea. Campinas, SP: 2017.

GONZÁLEZ REY, Fernando. Epistemología Cualitativa y Subjetividad. La Habana: Pueblo y Educación, 1997.

GONZÁLEZ REY, Fernando. Pesquisa qualitativa e subjetividade: os processos de construção da informação. 2. ed. Tradução de M. A. Ferrada Silva. São Paulo: Cengage Learning, 2005.

GONZÁLEZ REY, Fernando. Subjetividade e Saúde: superando a clínica da patologia. São Paulo: Cortez Editora, 2011.

GONZÁLEZ REY, Fernando. As categorias de sentido, sentido pessoal e sentido subjetivo: sua evolução e

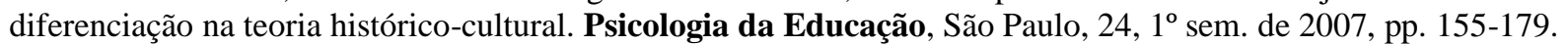

GONZÁLEZ REY, Fernando. Sujeito e subjetividade: uma aproximação histórico-cultural. Tradução de Raquel Souza Guzzo. São Paulo: Pioneira Thomson Learning, 2003.

GONZÁLEZ REY, Fernando; MITJÁNS MARTÍNEZ, Albertina; Rossato, Maristela; Goulart, Daniel Magalhães. The relevance of the concept of subjective configuration in discussing human development. In: FLEER, M., GONZÁLEZ REY, F., \& VERESOV, N. Cultural- historical perspectives on Emotions: Advancing the concepts of perezhivanie and subjectivity. Nova York: Springer, 2017, p. 297-338.

MÂCEDO, Cláudia Roberto Soares de. A criança com transtorno do espectro autista (TEA) e o professor: uma proposta de intervenção baseada na experiência de aprendizagem mediada (EAM). 2015. 163f. Dissertação (Mestrado em Educação) - Centro de Educação, Universidade Federal do Rio Grande do Norte, Natal, 2015.

MARCONI, Marina de Andrade; LAKATOS, Eva Maria. Técnica de pesquisa. 7. ed. São Paulo: Atlas, 2008.

MARTINS, Alessandra Dilair Formagio; MONTEIRO, Maria Inês Bacellar. Alunos autistas: análise das possibilidades de interação social no contexto pedagógico. Revista Psicologia Escolar e Educação, São Paulo, v. 21, n. 2, p.215-224, 2017. Maio - Agosto. Disponível em: <http://www.scielo.br/scielo.php?pid=S141385572017000200215\&script=sci_abstract\&tlng=pt>. Acesso em: 05 dez. 2017.

MOMO, Mariangela; MARTÍNEZ, Albertina Mitjáns. O trabalho pedagógico criativo na educação infantil diante da cultura da mídia e do consumo. Educação em Revista, [s.1.], v. 33, p.1-29, 2017. Disponível em: <http://www.scielo.br/scielo.php?script=sci_arttext\&pid=S0102-46982017000100120\&lng=pt\&tlng=pt>. Acesso em: 05 dez. 2017.

MOROSINI, M.C. Estado de conhecimento e questões do campo científico. Revista Educação. Santa Maria. v. 40, n. 1, p. 101-116. jan./abr. 2015.

MUNIZ, Luciana Soares; MARTÍNEZ, Albertina Mitjáns. A expressão da criatividade na aprendizagem da leitura e da escrita: um estudo de caso. Educação e Pesquisa, [s.1.], v. 41, n. 4, p.1039-1054, 10 abr. 2015. Disponível em: <http://www.scielo.br/scielo.php?script=sci_arttext\&pid=S1517-97022015000401039\&lng=pt\&tlng=pt>. Acesso em: 05 dez. 2017.

OLIVEIRA, Bruno Diniz Castro de et al. Políticas para o autismo no Brasil: entre a atenção psicossocial e a reabilitação1. Physis: Revista de Saúde Coletiva, [s.1.], v. 27, n. 3, p.707-726, jul. 2017. Disponível em: <http://www.scielo.br/scielo.php?script=sci_arttext\&pid=S0103-73312017000300707\&lng=pt\&tlng=pt>. Acesso em: 05 dez. 2017. 
PEREIRA, Eliane Candida. Os processos formativos do professor de alunos com transtorno do espectro autista: contribuições da teoria histórico-cultural. 2016. Dissertação (Mestrado em Educação) - Faculdade de Educação, Universidade de São Paulo, São Paulo, 2016.

RAMOS, Fabiane dos Santos. A Inclusão escolar de alunos com Transtorno do Espectro Autista em municípios da $4^{\mathrm{a}}$ colônia de imigração italiana, RS: um olhar sobre as práticas pedagógicas. 2014. 127 p. Dissertação (Mestrado) (Pós Graduação em Educação)- Universidade Federal de Santa Maria, Santa Maria, RS, 2014.

RINALDO, Simone Catarina de Oliveira . Processo educacional de crianças com Transtorno do Espectro Autista na Educação Infantil: interconexões entre contextos. 2016. 142 p. Dissertação (Programa de Pós-graduação em Educação Escolar)- Faculdade de Ciências e Letras - Campus de Araraquara, UNIVERSIDADE ESTADUAL PAULISTA, Araraquara, SP, 2016. Disponível em: <https://alsafi.ead.unesp.br/handle/11449/137895?show=full>. Acesso em: 07 fev. 2018.

RODRIGUES, Tatiane Pinto. Relações familiares e a escolarização de irmãos adolescentes de pessoas com TEA. 2015. 91 f. Dissertação (Mestrado em Educação) - Universidade Federal de Santa Maria, Santa Maria, 2015.

ROMANOWSKI, Joana Paulin; ENS, Romilda Teodora. As pesquisas denominadas do tipo Estado da Arte em educação. Diálogo educacional, Curitiba, v. 6, n.19, p. 37-50, set./dez. 2006. Disponível em: Acesso em 13 de abril de 2012.

ROSSATO, Maristela; MARTÍNEZ, Albertina Mitjáns. Desenvolvimento da subjetividade: análise de histórias de superação das dificuldades de aprendizagem. Revista Semestral da Associação Brasileira de Psicologia Escolar e Educacional, São Paulo, v. 17, n. 2, p.289-298, 2013. Julho/dezembro. Disponível em: <http://www.scielo.br/pdf/pee/v17n2/v17n2a11.pdf>. Acesso em: 05 dez. 2017.

SANTAROSA, Lucila Maria Costi; CONFORTO, Débora. Tecnologias móveis na inclusão escolar e digital de estudantes com transtornos de espectro autista. Revista Brasileira de Educação Especial, [s.1.], v. 21, n. 4, p.349-366, dez. 2015. Disponível em: <http://www.scielo.br/scielo.php?script=sci_arttext\&pid=S1413$65382015000400349 \& \operatorname{lng}=$ pt\&tlng=pt>. Acesso em: 05 dez. 2017.

SANTOS, Geandra Cláudia Silva; MARTÍNEZ, Albertina Mitjáns. A Subjetividade Social da Escola e os Desafios da Inclusão de Alunos com Desenvolvimento Atípico. Revista Brasileira de Educação Especial, [s.1.], v. 22, n. 2, p.253268, jun. 2016. Disponível em: <http://www.scielo.br/scielo.php?script=sci_arttext\&pid=S141365382016000200253\&lng=pt\&tlng=pt>. Acesso em: 05 dez. 2017.

SANTOS, Régia Vidal dos. A escolarização de crianças com transtorno do espectro autista: uma possibilidade de emancipação. 2016. 185 f. Dissertação( Programa de Mestrado em Gestão e Práticas Educacionais) - Universidade Nove de Julho, São Paulo.

TAKINAGA, Sofia Seixas. Transtorno do espectro autista: contribuições para a Educação Matemática na perspectiva da Teoria da Atividade. 2015. 127 f. Dissertação (Mestrado em Educação) - Pontifícia Universidade Católica de São Paulo, São Paulo, 2015.

TARDIF, Maurice. Saberes docentes e formação profissional. Petrópolis, RJ: Vozes, 2002.

TOMASI, Carolina; MEDEIROS, João Bosco. Comunicação científica: normas técnicas para redação científica. São Paulo: Atlas, 2008. 


\section{RESUMO}

Neste artigo, são apresentados os resultados de um mapeamento que teve como objetivo verificar se houve produções acadêmicas e artigos científicos que abordaram a interlocução entre Transtorno do Espectro Autista (TEA) e a Teoria da Subjetividade de Fernando González Rey (1997, 2003, 2017). O objetivo geral da pesquisa foi verificar se há uma abordagem científica que trate da constituição subjetiva da pessoa com TEA na perspectiva da Teoria da Subjetividade supracitada. Os dados estão apresentados neste artigo em forma de tabelas e quadros, buscando facilitar a visualização das produções elencadas para análise Dentre os resultados do mapeamento destaca-se que: um grande número de pesquisas e publicações que tratam sobre o TEA não são realizadas pela área da educação; as temáticas mais procuradas são as que remetem aos processos inclusivos e seus resultados; não foram encontradas pesquisas e produções que realizassem o encontro do TEA com a Teoria da Subjetividade. Desta forma, reforça-se a necessidade de aproximação destes conceitos, buscando uma nova forma de perceber a pessoa com TEA.

Palavras-chave: Transtorno do Espectro Autista. Teoria da Subjetividade

\section{THE SUBJECTIVITY THEORY AND THE AUTISTIC SPECTRUM DISORDER: WHAT HAS ALREADY BEEN SEARCHED?}

\section{SUMMARY}

This paper presents the results of a mapping that aimed to verify if there were academic productions and scientific articles that addressed the interlocution between Autism Spectrum Disorder (ASD) and Fernando González Rey's Theory of Subjectivity $(1997,2003,2017)$. The general objective of the research was to verify if there is a scientific approach that deals with the subjective constitution of the person with ASD from the perspective of the Subjectivity Theory mentioned above. The data are presented in this article in the form of tables and tables, seeking to facilitate the visualization of the productions listed for analysis. Among the results of the mapping it is highlighted that: a great number of researches and publications dealing with TEA are not carried out by the area of the education; the most sought topics are those that refer to inclusive processes and their results; no researches and productions were found that would hold the TEA meeting with Subjectivity Theory. In this way, the need to approach these concepts is strengthened, seeking a new way of perceiving the person with ASD.

Keywords: Autistic Spectrum Disorder. Subjectivity Theory

\section{LA TEORÍA DE LA SUBJETIVIDAD Y EL TRANSTORNO DEL ESPECTRO AUTISTA: - ¿QUÉ HAYA INVESTIDO?}

\section{RESUMEN}

En este artículo se presentan los resultados de un mapeamiento que tuvo como objetivo verificar si hubo producciones académicas y artículos científicos que abordaron la interlocución entre el Trastorno del Espectro Autista (TEA) y la Teoría de la Subjetividad de Fernando González Rey $(1997,2003,2017)$. El objetivo general de la investigación fue verificar si hay un enfoque científico que trate de la constitución subjetiva de la persona con TEA en la perspectiva de la Teoría de la Subjetividad anteriormente mencionada. Los datos se presentan en este artículo en forma de tablas y cuadros, buscando facilitar la visualización de las producciones enumeradas para análisis. Entre los resultados del mapeo se destaca que: un gran número de investigaciones y publicaciones que tratan sobre el TEA no son realizadas por el área de la TEA, la educación; las temáticas más buscadas son las que remiten a los procesos inclusivos y sus resultados; no se encontraron investigaciones y producciones que realizaran el encuentro del TEA con la Teoría de la Subjetividad. De esta forma, se refuerza la necesidad de aproximación de estos conceptos, buscando una nueva forma de percibir a la persona con TEA.

Palabras clave: Trastorno del Espectro Autista. Teoría de la Subjetividad

Submetido em 02 de fevereiro de 2019 Aceito em 30 de agosto de 2019 